\title{
LEVELS AND HEALTH RISK ASSESSMENT OF PM AEROSOL IN BRNO, CZECH REPUBLIC
}

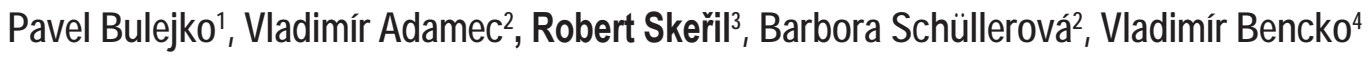 \\ ${ }^{1}$ Heat Transfer and Fluid Flow Laboratory, Faculty of Mechanical Engineering, Brno University of Technology, Brno, Czech Republic \\ ${ }^{2}$ Department of Risk Engineering, Institute of Forensic Engineering, Brno University of Technology, Brno, Czech Republic \\ ${ }^{3}$ Czech Hydrometeorological Institute, Brno Regional Office, Brno, Czech Republic \\ ${ }^{4}$ Institute of Hygiene and Epidemiology, First Faculty of Medicine, Charles University and General University Hospital, Prague, Czech Republic
}

\section{SUMMARY}

Objective: The main effort of this work was to evaluate the situation of the atmosphere in selected regions of Brno during the years 2009-2013 and to estimate health risks which might come up due to the increased concentrations of airborne particulate matter.

Methods: $\mathrm{PM}_{10}$ samples were collected in four areas varying in degree of automobile traffic using automatic and gravimetric sampling methods. $\mathrm{PM}_{10}$ concentrations were assessed using Spearman's rank correlation coefficient. Health risks were estimated based on calculation of relative risks and population for four health endpoints. The selected health outcomes were premature mortality, cardiovascular disease, respiratory disease, and chronic bronchitis.

Results: The highest $\mathrm{PM}_{10}$ concentrations were measured in two regions with high traffic loads $\mathrm{T} 1, \mathrm{~T} 2$ and background region $\mathrm{B} 2$. The values were $34.33 \pm 11.52 \mu \mathrm{g} \cdot \mathrm{m}^{-3}$ in $2010,34.87 \pm 12.03 \mu \mathrm{g} \cdot \mathrm{m}^{-3}$ in 2013 and $34.52 \pm 8.81 \mu \mathrm{g} \cdot \mathrm{m}^{-3}$ in 2009 , respectively. The highest correlation was between T1 and T2 having Spearman's correlation coefficient 0.888 followed by T1-B1 pair with coefficient 0.886 . For all health outcomes, the highest health effect of PM (E) was determined for T2 site in 2010 which was $48 \pm 14,49 \pm 21,44 \pm 19$ and $24 \pm 10$ for premature mortality, cardiovascular disease, respiratory disease, and chronic bronchitis, respectively.

Conclusion: The concentrations are highly correlated, especially in traffic regions. The annual concentrations did not exceed the legislation limit but 24-hours limit was exceeded more than two times in several cases. The highest number of cases with a given health outcome was estimated in traffic regions especially for cardiovascular disease and premature mortality.

Key words: traffic, particulate matter, air pollution, aerosol, risk assessment, public health

Address for correspondence: P. Bulejko, Heat Transfer and Fluid Flow Laboratory, Faculty of Mechanical Engineering, Brno University of Technology, Technická 2, 61669 Brno, Czech Republic. E-mail: Pavel.Bulejko@vut.cz

https://doi.org/10.21101/cejph.a4495

\section{INTRODUCTION}

An increasing amount of particulate matter (PM) in large cities has been a problem for many years. It has been found that there is a direct relationship between increased concentrations of PM and human health disorders. Respiratory, cardiovascular and cerebrovascular diseases, allergies, asthma, and cancer are the most frequent consequences (1-4). Generally, it is distinguished between $\mathrm{PM}_{10}$ and $\mathrm{PM}_{2.5} . \mathrm{PM}_{10}$ are particles with diameter less than $10 \mu \mathrm{m}$ while $\mathrm{PM}_{2.5}$ are those with diameter less than $2.5 \mu \mathrm{m}$ (5). More recently, ultra-fine particles $\mathrm{PM}_{1}$ (particles smaller than $1 \mu \mathrm{m}$ ) and nanoparticles derived from traffic exhaust (6) begin to be measured in urban environment.

Air pollution has been a long-term problem in the Czech Republic (CR). The largest sources of air contamination include thermal power plants and industry, automobile traffic, local heating and waste combustion. In the 1970s and 1980s, the air pollution levels in some industrial areas were among the highest in Europe (7). After 1989, a number of steps were introduced to reduce the air pollution, especially in the energy sector and other heavy industries. For example, in the 1990s, there was the
Teplice project which was aimed to solve air pollution problems in northern part of the Czech Republic (8). After 2000, there was a reversal of the trend and the concentrations of many pollutants rose again (9). According to model calculations performed by the National Institute of Public Health, overall mortality caused by exposure to $\mathrm{PM}_{10}$ throughout the Czech Republic increased between 2006 and 2010 (10).

Today, pollution from suspended particles remains a problem in the Czech Republic. In 2013, the 24-hour PM $_{10}$ limit of 50 $\mu \mathrm{g} \cdot \mathrm{m}^{-3}$ (11) was exceeded in $5.7 \%$ of $\mathrm{CR}$ and the average annual $\mathrm{PM}_{10}$ limit of $40 \mu \mathrm{g} \cdot \mathrm{m}^{-3}$ was exceeded in $0.7 \%$ of CR. These areas correspond to approximately $15.9 \%$ and $4.8 \%$ of residents, respectively. With respect to human health effects, the main cause of PM emissions is due to traffic, especially from fuel combustion in diesel engines. These engines produce particles with sizes of up to hundreds of nanometers (6).

Several studies have been carried out concerning PM air pollution in Brno (12-20). However, most of them are focused on PM-bound substances such as heavy metals or polycyclic aromatic hydrocarbons. To consider the health effect of PM itself, it is necessary to assume that the particles are inert (without any effect of 
bound substances). So the whole health risk assessment procedure will substantially differ from those carried out for the PM-bound substances. The main effort of this study was to evaluate the $\mathrm{PM}_{10}$ pollution in Brno city over five-year period (2009-2013) and to estimate associated health risks expressed by the number of people with given health outcome and increased mortality.

\section{MATERIALS AND METHODS}

\section{Sampling Sites}

Sampling was performed in four regions with varying degrees of automobile traffic (Fig. 1). Two background regions (residential areas referred to as B1 and B2 in this text) and two regions with high traffic loads (referred to as T1 and T2) were studied. Table 1 shows basic features of sampling sites. Generally, T1 and T2 are traffic sites with high automobile traffic load with measuring stations placed right next to the main road. Conversely, B1 is a residential site at a periphery of Brno city not influenced by traffic load. B2 is also background site, however, it is situated in the vicinity of main road to the city centre in a distance of $1 \mathrm{~km}$ from T2 site. So, even though the B2 site is considered background (as defined by the Czech Hydrometeorological Institute), there is direct influence from traffic load. The $\mathrm{PM}_{10}$ sampling was performed at different intervals (Table 1).

\section{Automatic and Gravimetric Sampling}

In automatic sampling, aerosol particles are caught on a filtration belt made of glass fibers using a vacuum. The filtration belt

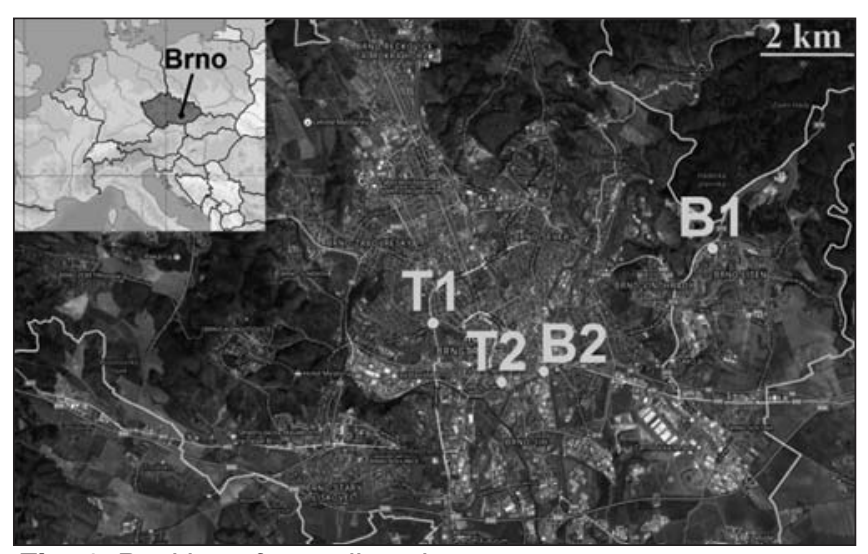

Fig. 1. Position of sampling sites. automatically unreels between a beta-emitter and a Geiger-Müller counter. The difference between radiations before and after the aerosol particles are captured represents the amount of dust aerosol particles on the filter. The aerosol particles are drawn in using a vacuum pump with a sampling head connected to the top section of the analyzer with a flow rate of $1 \mathrm{~m}^{3} \cdot \mathrm{h}^{-1}$. For the gravimetric method, an FH 95 SEQ sequential particulate sampler was used to determine manual mass concentration of suspended particulates in the ambient air. The sampled particulate is determined by balancing the filter before and after sampling. The atmospheric concentration of particulates $\left(\mu \mathrm{g} \cdot \mathrm{m}^{-3}\right)$ is the ratio of the weight of particulates and the volume of air which passed through the filter.

\section{Health Risk Assessment}

Long-term elevated concentrations of suspended particles contribute to the occurrence of various symptoms of respiratory deterioration, increased morbidity and mortality (21, 22). Mortality is often used to illustrate the negative impacts of suspended particles $(13,20)$. The basic assumption for estimating the health risk of PM is calculation of the risk by $1 \mu \mathrm{g} \cdot \mathrm{m}^{-3}$ increment if the PM concentration exceeds the safe limit. Based on the population of one city the health impact can be estimated. Four health endpoints were selected to assess the health risk by $\mathrm{PM}_{10}$ pollution, i.e. premature mortality, respiratory and cardiovascular disease and chronic bronchitis.

The relative risk (RR) for the given health outcome can be calculated using the following equation $(23,24)$ :

$$
R R=e^{\beta\left(C-C_{0}\right)}
$$

For premature mortality, the formula is as follows (23):

$$
R R=\left(\frac{C+1}{C_{0}+1}\right)^{\beta}
$$

where $\beta$ is an empirical coefficient (a percentage increase in health effect per $1 \mu \mathrm{g} \cdot \mathrm{m}^{-3} \mathrm{PM}$ increment) for given health outcome, $\mathrm{C}$ and $\mathrm{C}_{0}$ are the real $\mathrm{PM}$ concentration and the PM reference concentration, respectively. The $\beta$ coefficient (with $95 \%$ confidence interval) is $0.073(0.045,0.101), 0.0007(0.0005$, $0.0009), 0.0012(0.0010,0.0014)$, and $0.0048(0.0044,0.0052)$ for premature mortality, cardiovascular disease, respiratory disease and chronic bronchitis, respectively. The reference concentration $\mathrm{C}_{0}$ of $20 \mu \mathrm{g} \cdot \mathrm{m}^{-3}$ was applied according to WHO air quality guideline (25).

Table 1. Basic features of sampling sites

\begin{tabular}{|l|c|c|c|c|}
\hline Location & B1 & B2 & T1 & T2 \\
\hline Station type & Background & Background & Traffic & Traffic \\
\hline Zone type & Urban & Urban & Urban & Urban \\
\hline Zone feature & Residential & Residential, trade & Residential & Trade \\
\hline Latitude & $49^{\circ} 12^{\prime} 47.57^{\prime \prime}(\mathrm{N})$ & $49^{\circ} 11^{\prime} 20.00^{\prime \prime}(\mathrm{N})$ & $49^{\circ} 11^{\prime} 53.12^{\prime \prime}(\mathrm{N})$ & $49^{\circ} 11^{\prime} 9.18^{\prime \prime}(\mathrm{N})$ \\
\hline Longitude & $16^{\circ} 40^{\prime} 40.65^{\prime \prime}(\mathrm{E})$ & $16^{\circ} 37^{\prime} 37.00^{\prime \prime}(\mathrm{E})$ & $16^{\circ} 35^{\prime} 37.12^{\prime \prime}(\mathrm{E})$ & $16^{\circ} 36^{\prime} 49.18^{\prime \prime}(\mathrm{E})$ \\
\hline Altitude & $340 \mathrm{~m}$ & $214 \mathrm{~m}$ & $235 \mathrm{~m}$ & $200 \mathrm{~m}$ \\
\hline Measuring frequency & 1 per 2 days & 1 per day & 1 per day & 1 per hour \\
\hline
\end{tabular}


The number of cases for given health effect of PM (E) is calculated based on the difference in the current incidence rate (fp) and the incidence rate in a clean environment (fc) as follows (24):

$$
E=P\left(f_{\mathrm{p}}-f_{\mathrm{c}}\right)
$$

where $\mathrm{P}$ is number of people in the population of interest. The current incidence rate fp can be calculated using the relative risk as follows:

$$
f_{\mathrm{p}}=f_{\mathrm{c}} R R
$$

Substituting the 4th equation into 3rd equation, the number of cases for given health outcome is obtained:

$$
E=\frac{R R-1}{R R} f_{\mathrm{p}} P
$$

The values of fp were obtained from Health statistics yearbook of the South Moravia Region (26) and are 0.0088, 0.0269, 0.0124 and 0.0020 for premature mortality, cardiovascular disease, respiratory disease and chronic bronchitis, respectively. Cardiovascular diseases included such diagnoses as acute rheumatic fever, acute and subsequent myocardial infarction, cerebrovascular diseases, atherosclerosis, angina pectoris etc. Respiratory disease is a general term for such illnesses as pneumonia, asthma, acute tonsillitis, influenza, and chronic obstructive pulmonary diseases (COPD) including emphysema and chronic bronchitis. However, chronic bronchitis was calculated separately as individual health outcome similarly to many other studies $(23,24)$.

\section{Statistical Analysis}

The data was firstly tested for normality using the Shapiro-Wilk test. Then the correlation analysis was carried out to assess the depedence of $\mathrm{PM}_{10}$ concentrations between individual sites. For an overview of the single dependences, a matrix of scatterplots was created and provided with prediction bands of coverage probability of 0.95 and Spearman's rank correlation coefficients using StatSoft Statistica 12 software.

\section{RESULTS AND DISCUSSION}

\section{$\mathbf{P M}_{10}$ Concentration}

Fig. 2 shows the $\mathrm{PM}_{10}$ concentrations (monthly variations) in the investigated areas during 2009-2013. The highest concentra- tion of $\mathrm{PM}_{10}$ is observable in the $\mathrm{T} 1, \mathrm{~T} 2$ and $\mathrm{B} 2$ regions, which is reasonable due to the high traffic load. Even though the B2 site is considered, it is situated in the vicinity of main road (in a distance of about $50 \mathrm{~m}$ ) to the city centre so the concentration are sometimes even higher than in the traffic areas. This can be also due to local heating as B2 is residential area, so this contribution together with traffic load could cause even higher concentrations than in T1 and T2. All curves have a similar shape and from 2009 to 2013 are characterized by a downward trend. The highest values are observable at the beginning (2009) and over time the concentration of $\mathrm{PM}_{10}$ decreases (e.g. in T2 from about $70 \mu \mathrm{g} \cdot \mathrm{m}^{-3}$ in 2009 to about $40 \mu \mathrm{g} \cdot \mathrm{m}^{-3}$ in 2013). For all localities the $\mathrm{PM}_{10}$ concentration in winter increases compared to the summer. The main cause is a higher amount of combustion wastes which are released due to increased local heating. Winter is the most polluted season also because of very low precipitation and frequent thermal inversions causing deterioration of vertical diffusion conditions.

Table 2 shows annual averages of $\mathrm{PM}_{10}$ concentrations (with standard deviation), with the number of $\mathrm{PM}_{10}$ concentration exceedances. The annual averages are not exceeded, however, the number of days of exceeded daily concentration is very high, in some cases even more than two times of the legislation limit. The highest daily values reach figures three times higher than the limit. For background regions, the limits were exceeded only in two cases. Table 3 shows the results of PM measurements from different studies throughout Europe compared with this study. Region T2 (annual average of 2010) was chosen for comparison due to the highest level of $\mathrm{PM}_{10}$ pollution. $\mathrm{PM}_{10}$ concentration was higher in several cases. It is clear from this comparison that the atmosphere in CR is one of the worst in Europe even though

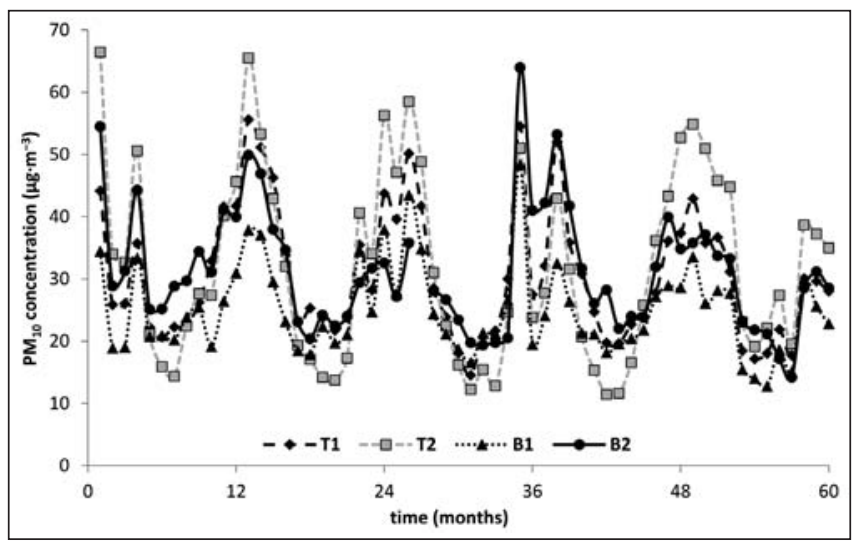

Fig. 2. Concentration of $P M_{10}$ during 2009-2013 (monthly average values).

Table 2. Concentration of $P M_{10}$ - annual average \pm standard deviation $\left(\mu \mathrm{g} \cdot \mathrm{m}^{-3}\right)$ / number of exceeded daily concentrations during the years

\begin{tabular}{|l|c|c|c|c|}
\hline & T1 & T2 & B1* & B2 $^{*}$ \\
\hline 2009 & $30.16 \pm 8.66 / 35$ & $33.19 \pm 15.35 / 68$ & $24.43 \pm 5.71 / 7$ & $34.52 \pm 8.81 / 45$ \\
\hline 2010 & $34.33 \pm 11.52 / 59$ & $33.84 \pm 17.26 / 75$ & $27.00 \pm 7.57 / 13$ & $31.43 \pm 9.21 / 26$ \\
\hline 2011 & $30.90 \pm 12.28 / 45$ & $30.33 \pm 15.92 / 59$ & $26.97 \pm 9.70 / 23$ & $29.58 \pm 12.74 / 24$ \\
\hline 2012 & $30.32 \pm 8.83 / 33$ & $27.98 \pm 13.03 / 44$ & $24.15 \pm 4.27 / 15$ & $33.30 \pm 9.04 / 30$ \\
\hline 2013 & $27.29 \pm 8.26 / 19$ & $34.87 \pm 12.03 / 69$ & $22.48 \pm 6.76 / 10$ & $27.13 \pm 7.20 / 5$ \\
\hline
\end{tabular}

*Number of days exceeding is tentative $-\mathrm{PM}_{10}$ is measured 2 days out of 3 in $\mathrm{B} 1$ and $\mathrm{B} 2$ is on a $14 \mathrm{~d}$ period - daily measurements. 
Table 3. Comparison of PM levels with different studies throughout Europe

\begin{tabular}{|l|c|c|c|}
\hline Country & Site & $\mathbf{P M}_{10}\left(\mu g^{-3} \mathbf{m}^{-3}\right.$ & Reference \\
\hline Czech Republic & Brno T2 in 2010) & 35.7 & This study \\
\hline Sweden & Stockholm & 55 & $(27)$ \\
\hline France & Marseille & 23 & $(28)$ \\
\hline Switzerland & Bern & 32.5 & $(30)$ \\
\hline UK & Birmingham & 23.9 & $(31)$ \\
\hline Italy & Milan & 37 & $(32)$ \\
\hline Spain & Madrid & 34.4 & $(33)$ \\
\hline Turkey & Istanbul & 70 & \\
\hline
\end{tabular}

the Czech Republic is one of Europe's smaller countries by area and also by number of inhabitants.

Concentrations of $\mathrm{PM}_{10}$ at individual sites are in positive correlation as assessed by Spearman's rank correlation coefficients. These correlations are statistically significant at a level of significance of 0.01 as confirmed by Student's t test. The Spearman's rank correlation coefficient was selected since the data have non-normal distribution as confirmed by Shapiro-Wilk test. The positive correlation in $\mathrm{PM}_{10}$ concentrations between individual sampling sites implies that the pollution may be caused by the same sources. The strongest correlation for $\mathrm{PM}_{10}$ concentrations is between $\mathrm{T} 1$ and T2 (traffic sites) which proves the main source of pollution in these areas, i.e. automobile traffic. However, all correlation coefficients exceeded 0.7, which confirms a high level of correlation for all pairs of regions (Fig. 3). High level of correlation between background and traffic sites also indicate common sources influenced by local heating, dust resuspension and also influence of construction sites in the vicinity of measuring stations.

\section{Health Impact of $\mathbf{P M}_{10}$ Pollution}

The number of people affected by a given health outcome (E) in given locality and year are shown in Table 4 . For simplicity, the number of cases was calculated per 100,000 inhabitants. Generally, several trends can be observed. Firstly, concerning individual localities, E decreased in order $\mathrm{T} 2>\mathrm{T} 1>\mathrm{B} 2>\mathrm{B} 1$ for all health outcomes. Secondly, the highest $\mathrm{E}$ was for cardiovascular disease followed by premature mortality. The lowest $\mathrm{E}$ was predicted for chronic bronchitis. This could seem a contradiction because chronic bronchitis is a health outcome often caused by air pollution. However, this is especially in heavy polluted industrial sites such as those in developing countries, e.g. in China $(23,24)$. Moreover, the current incidence rate for chronic bronchitis is based on the number of hospital admissions of South Moravia region which does not distinguish various causes of this health outcome. Generally, the major cause of chronic bronchitis is tobacco smoking followed by air pollution and genetic factors. For all health outcomes, the highest $\mathrm{E}$ was determined for T2 site in 2010 which was $48 \pm 14$,
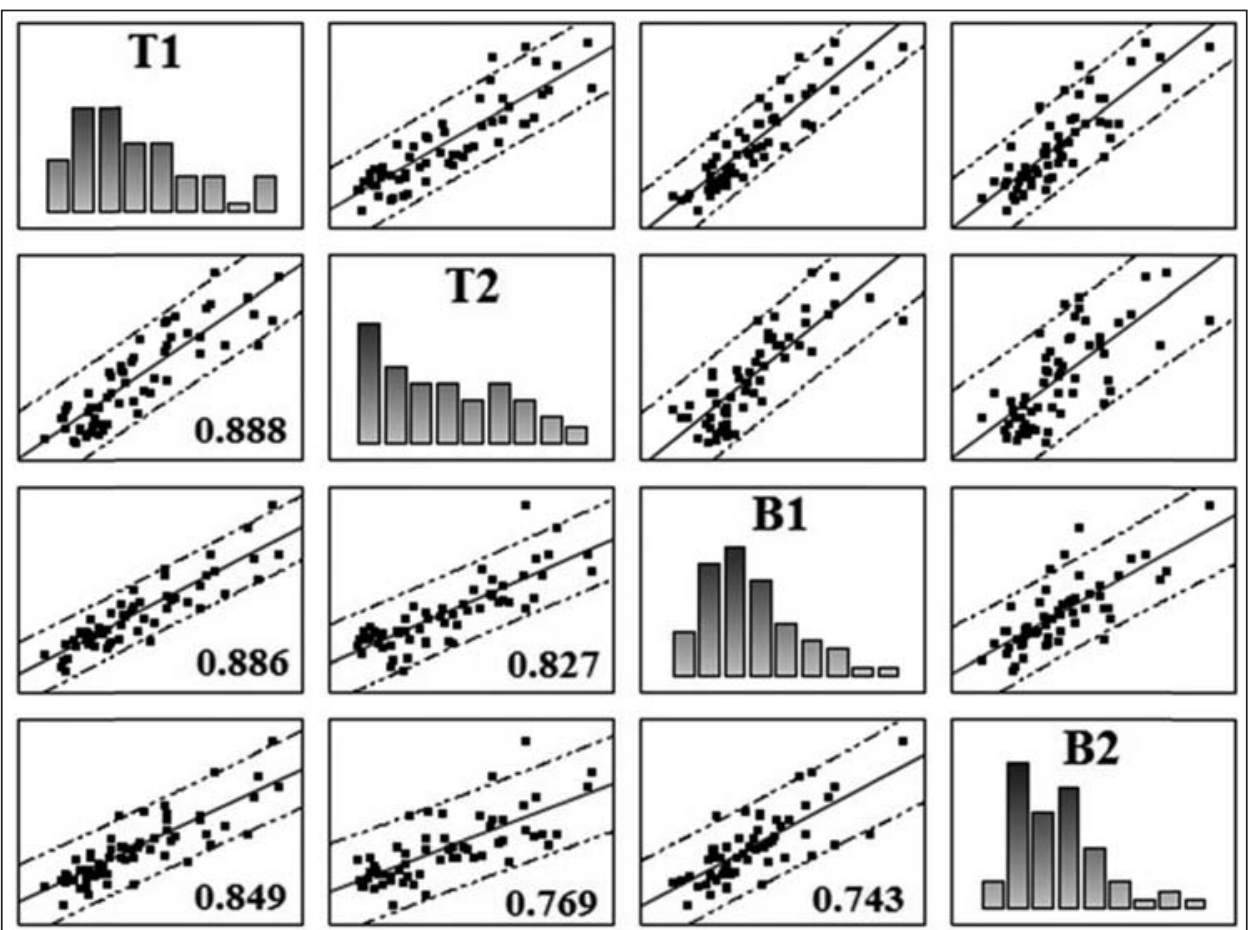

Fig. 3. Scatterplot matrix of $P M_{10}$ concentration between individual sites with prediction bands of $95 \%$ coverage probability and values of Spearman's rank correlation coefficients. 
Table 4. Number of cases \pm standard deviation per 100,000 inhabitants for selected health outcomes in all localities during 2009-2013

\begin{tabular}{|l|c|c|c|c|c|c|c|c|}
\hline \multirow{2}{*}{} & \multicolumn{4}{|c|}{ Premature mortality } & \multicolumn{4}{c|}{ Cardiovascular diseases } \\
\cline { 2 - 9 } & T1 & T2 & B1 & B2 & T1 & T2 & B1 & B2 \\
\hline 2009 & $22 \pm 16$ & $32 \pm 21$ & $15 \pm 12$ & $31 \pm 14$ & $19 \pm 16$ & $31 \pm 26$ & $12 \pm 10$ & $27 \pm 16$ \\
\hline 2010 & $29 \pm 19$ & $48 \pm 14$ & $22 \pm 14$ & $24 \pm 17$ & $27 \pm 21$ & $49 \pm 21$ & $18 \pm 13$ & $21 \pm 17$ \\
\hline 2011 & $28 \pm 19$ & $35 \pm 22$ & $21 \pm 17$ & $26 \pm 20$ & $26 \pm 21$ & $34 \pm 25$ & $18 \pm 18$ & $25 \pm 24$ \\
\hline 2012 & $27 \pm 14$ & $31 \pm 17$ & $13 \pm 9$ & $28 \pm 16$ & $23 \pm 15$ & $28 \pm 19$ & $10 \pm 7$ & $25 \pm 17$ \\
\hline 2013 & $27 \pm 11$ & $35 \pm 18$ & $19 \pm 7$ & $22 \pm 12$ & $22 \pm 11$ & $34 \pm 20$ & $14 \pm 6$ & $18 \pm 10$ \\
\hline & \multicolumn{9}{|c|}{ Respiratory diseases } & & \multicolumn{4}{|c|}{ Chronic bronchitis } \\
\hline 2009 & $17 \pm 15$ & $28 \pm 24$ & $11 \pm 9$ & $25 \pm 15$ & $9 \pm 8$ & $15 \pm 12$ & $6 \pm 5$ & $13 \pm 8$ \\
\hline 2010 & $24 \pm 19$ & $44 \pm 19$ & $17 \pm 11$ & $19 \pm 16$ & $13 \pm 10$ & $24 \pm 10$ & $9 \pm 6$ & $10 \pm 8$ \\
\hline 2011 & $23 \pm 19$ & $31 \pm 23$ & $17 \pm 16$ & $22 \pm 22$ & $13 \pm 10$ & $17 \pm 12$ & $9 \pm 9$ & $12 \pm 11$ \\
\hline 2012 & $21 \pm 14$ & $26 \pm 17$ & $9 \pm 7$ & $23 \pm 15$ & $11 \pm 7$ & $14 \pm 9$ & $5 \pm 4$ & $12 \pm 8$ \\
\hline 2013 & $20 \pm 10$ & $30 \pm 18$ & $13 \pm 5$ & $16 \pm 9$ & $11 \pm 5$ & $16 \pm 9$ & $7 \pm 3$ & $9 \pm 5$ \\
\hline
\end{tabular}

$49 \pm 21,44 \pm 19$ and $24 \pm 10$ for premature mortality, cardiovascular disease, respiratory disease and chronic bronchitis, respectively. This is reasonable as T2 is traffic site where the highest concentrations of $\mathrm{PM}_{10}$ were measured. Similarly, in relation to type of region, B1 site (background, residential) was the one with lowest E for all diagnoses due to lower $\mathrm{PM}_{10}$ concentrations compared to the other sites. The highest $\mathrm{E}$ at this site was for premature mortality in 2010 and 2011 i.e. $22 \pm 14$ and $21 \pm 17$ cases, respectively.

\section{CONCLUSION}

Based on the results presented above, the following conclusions were made. $\mathrm{PM}_{10}$ concentrations did not exceed permitted annual limit of $40 \mu \mathrm{g} \cdot \mathrm{m}^{-3}$. However, the number of days with higher concentration than the 24-hours limit (the 24-hours limit is $50 \mu \mathrm{g} \cdot \mathrm{m}^{-3}$, max 35 days per year) was exceeded every year in T2, in 2010 and 2011 in T1, and in 2009 in B2. In B1 the limit was not exceeded. The concentrations between individual sites are in a strong positive correlation. The traffic sites are correlated at the most indicating the main source high traffic load. High level of correlation between background and traffic sites also indicate common sources influenced by local heating, dust resuspension and also by construction sites in the vicinity of measuring stations. The health risk assessment showed increased risk for people exposed to PM pollution. There is a high risk of increased number of cases with cardiovascular diseases, premature mortality and respiratory outcomes especially in T2 site. Conversely, B1 site with low level of traffic load poses lower health risk.

These results show how transportation is important for air quality in the city centre. While the concentrations in the background stations in housing estates do not exceed the limits, traffic stations in the city centre exceed air quality limits every year.

\section{Acknowledgements}

The research leading to these results has received funding from the Ministry of Education, Youth and Sports under the National Sustainability Programme I (Project LO1202). Data were provided by the Czech Hydrometeorological Institute, Brno Regional Office.

\section{Conflict of Interests}

None declared

\section{REFERENCES}

1. Darçın M. Association between air quality and quality of life. Environ Sci Pollut Res Int. 2014 Feb;21(3):1954-9. doi:10.1007/s11356-0132101-3.

2. Luo C, Zhu X, Yao C, Hou L, Zhang J, Cao J, et al. Short-term exposure to particulate air pollution and risk of myocardial infarction: a systematic review and meta-analysis. Environ Sci Pollut Res Int. 2015 Oct;22(19):14651-62. doi:10.1007/s11356-015-5188-x.

3. Leiva G MA, Santibañez DA, Ibarra E S, Matus C P, Seguel R. A fiveyear study of particulate matter (PM2.5) and cerebrovascular diseases. Environ Pollut. 2013 Oct;181:1-6. doi: 10.1016/j.envpol.2013.05.057.

4. Štych P, Šrámková D, Braniš M. Assessment of exposure of elementary schools to traffic pollution by GIS Methods. Cent Eur J Public Health. 2016 Jun;24(2):109-14.

5. Velická H, Puklová V, Keder J, Brabec M, Malý M, Bobák M, et al. Asthma exacerbations and symptom variability in children due to shortterm ambient air pollution changes in Ostrava, Czech Republic. Cent Eur J Public Health. 2015 Dec;23(4):292-8.

6. Hurbánková M, Černá S, Kováčiková Z, Wimmerová S, Hrašková D, Marcišiaková J, et al. Effect of TiO2 nanofibres on selected bronchoalveolar parameters in acute and subacute phase - experimental study. Cent Eur J Public Health. 2013 Sep;21(3):165-70.

7. Horák J, Malíková O. Environmentally related impacts on financial reporting: the case of pollution permits in Czech legislative conditions. In: Brebbia CA, Longhurst JWS, Popov V, editors. Air Pollution XIX. Southampton: WIT Press; 2011. p. 433-42.

8. Leníček J, Sekyra M, Pandey P, Čítková M, Beneš I, Novotná J, et al. Polycyclic aromatic hydrocarbons at 'program Teplice' sites in the Czech republic. Toxicol Environ Chem. 2008; 58,(1-4):25-32. doi:10.1080/02772249709358395.

9. Macoun, J. History, present days and prospects of the air quality control in the Czech Hydrometeorological Institute. Meteorol Bull. 2009;62(5): 153-6. (In Czech.)

10. ISSaR. Health risk of air pollution. Core set of environmental indicators of the Czech Republic [Internet]. ISSaR; 2011 [cited 2015 Jan 27]. Available from: http://issar.cenia.cz/issar/page.php?id=1900.

11. Air Protection Act. Act no. 201/2012 Coll. Supplement no. 1 to Act no. 201/2012 Coll. The limit and the permitted number of exceedances per calendar year. Sbir Zak CR. 2012(částka 69):2822-48. (In Czech.)

12. Veselý V, Tonner J, Hrdličková Z, Michálek J, Kolář M. Analysis of PM10 air pollution in Brno based on generalized linear model with strongly rank-deficient design matrix. Environmetrics. 2009 Sep; 20(6):676-98. doi: 10.1002/env.971. 
13. Adamec V, Ličbinský R, Schwarzová M, Huzlík J. Health risks of harmful compounds fixed on particulate matter (PM2.5) in urban air. Chem Listy. 2007;101(S2):78-80.

14. Hrdličková Z, Michálek J, Kolář M, Veselý V. Identification of factors affecting air pollution by dust aerosol PM10 in Brno City, Czech Republic. Atmos Environ. 2008 Dec;42(37):8661-73. doi: 10.1016/j. atmosenv.2008.08.017.

15. Stadlober E, Hübnerová Z, Michálek J, Kolář M. Forecasting of daily PM10 concentrations in Brno and Graz by different regression approaches. Austrian Journal of Statistics. 2012;41(4):287-310.

16. Čupr P, Flegrová Z, Franců J, Landlová L, Klánová J. Mineralogical, chemical and toxicological characterization of urban air particles. Environ Int. 2013 Apr;54:26-34. doi: 10.1016/j.envint.2012.12.012.

17. Hübnerová Z, Michalek J. Analysis of daily average PM10 predictions by generalized linear models in Brno, Czech Republic. Atmos Pollut Res. 2014 Jul;5(3):471-6. doi: 10.5094/apr.2014.055.

18. Bumbová A, Adamec V, Navrátil J, Ješonková L, Langerová A. Health risk assessment of air pollution caused by polycyclic aromatic hydrocarbons bound to particulate matter smaller than $1 \mu \mathrm{m}$. In: Mladenov V, Psarris K, Mastorakis N, Caballero A, Vachtsevanos G, editors. Development , energy, environment, economics: International Conference on Development, Energy, Environment, Economics (DEEE'10); 2010 Nov 30-Dec 2; Puerto de la Cruz, Tenerife. WSEAS Press; 2010. p. 218-23.

19. Bulejko P, Adamec V, Schüllerová B, Skeřil R. Levels, sources, and health risk assessment of polycyclic aromatic hydrocarbons in Brno, Czech Republic: a 5-year study. Environ Sci Pollut Res Int. 2016 Oct;23(20):20462-20473. doi:10.1007/s11356-016-7172-5.

20. Ciganek M, Neca J, Adamec V, Janosek J, Machala M. A combined chemical and bioassay analysis of traffic-emitted polycyclic aromatic hydrocarbons. Sci Total Environ. 2004 Dec 1;334-335:141-8. doi:10.1016/j. scitotenv.2004.04.034.

21. Bencko V. Use of epidemiological data for cancer risk assessment: approaches, concepts, and issuess. Open Epidemiol J. 2011 Jan;4:94-8. doi: $10.2174 / 1874297101104010094$.

22. Bencko V, Vostal J. Air pollution by solid particles and public health: when can we conclude on causality. Cent Eur J Public Health. 1999;7(2):63-6.

23. Cheng Z, Jiang J, Fajardo O, Wang S, Hao J. Characteristics and health impacts of particulate matter pollution in China (2001-2011). Atmos Environ 2013;65:186-94. doi:10.1016/j.atmosenv.2012.10.022.

24. Song Y, Wang X, Maher BA, Li F, Xu C, Liu X, et al. The spatialtemporal characteristics and health impacts of ambient fine particulate matter in China. J Clean Prod. 2016;112(Part 2):1312-18. doi:10.1016/j. jclepro.2015.05.006.
25. World Health Organization. Air quality guidelines for particulate matter, ozone, nitrogen dioxide and sulfur dioxide: global update 2005 [Internet]. Geneva: WHO; 2005 [cited 2017 Jan 15]. Available from: http://apps.who. int/iris/bitstream/10665/69477/1/WHO_SDE_PHE_OEH_06.02_eng. pdf.

26. Institute of Health Information and Statistics of the Czech Republic. Health statistics yearbook of the Jihomoravský Region 2013 [Internet]. Brno: Institute of Health Information and Statistics of the Czech Republic; 2014 [cited 2017 Jan 15]. Available from: http://www.uzis.cz/katalog/rocenky/zdravotnicka-rocenka-jihomoravskeho-kraje. (In Czech, English.)

27. Johansson C, Johansson P. Particulate matter in the underground of Stockholm. Atmos Environ. 2003 Jan;37(1):3-9. doi: 10.1016/S13522310(02)00833-6.

28. Pascal M, Falq G, Wagner V, Chatignoux E, Corso M, Blanchard M, et al. Short-term impacts of particulate matter (PM10, PM10-2.5, PM2.5) on mortality in nine French cities. Atmos Environ. 2014 Oct;95:175-84. doi: 10.1016/j.atmosenv.2014.06.030.

29. Gehrig R, Buchmann B. Characterising seasonal variations and spatial distribution of ambient PM10 and PM2.5 concentrations based on longterm Swiss monitoring data. Atmos Environ. 2003 Jun;37(19):2571-80. doi: 10.1016/S1352-2310(03)00221-8.

30. Yin J, Harrison RM. Pragmatic mass closure study for PM1.0, PM2.5 and PM10 at roadside, urban background and rural sites. Atmos Environ. 2008 Feb;42(5):980-8. doi: 10.1016/j.atmosenv.2007.10.005.

31. Colombi C, Angius S, Gianelle V, Lazzarini M. Particulate matter concentrations, physical characteristics and elemental composition in the Milan underground transport system. Atmos Environ. 2013 May;70:166-78. doi: 10.1016/j.atmosenv.2013.01.035.

32. Jiménez E, Linares C, Rodríguez LF, Bleda MJ, Díaz J. Short-term impact of particulate matter (PM2.5) on daily mortality among the over-75 age group in Madrid (Spain). Sci Total Environ. 2009 Oct 15;407(21):548692. doi:10.1016/j.scitotenv.2009.06.038.

33. Şahin ÜA, Onat B, Stakeeva B, Ceran T, Karim P. PM10 concentrations and the size distribution of $\mathrm{Cu}$ and Fe-containing particles in Istanbul's subway system. Transp Res D Transp Environ. 2012 Jan;17(1):48-53. doi: 10.1016/j.trd.2011.09.003.

Received July 12, 2015

Accepted in revised form January 15, 2017 